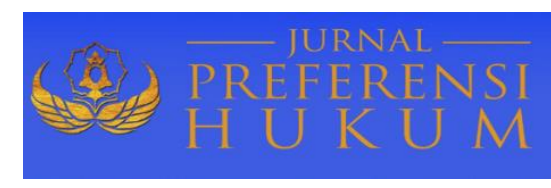

Jurnal Preferensi Hukum | ISSN: 2746-5039

Vol. 2, No. 1 - Februari 2021, Hal. 207-212| Available online at

https://www.ejournal.warmadewa.ac.id/index.php/juprehum

DOI: https://doi.org/10.22225/jph.2.1.3069.207-212

\title{
PENERAPAN SANKSI PEMERINTAHAN PADA PT. MIRTASARI DEVELOPMENT
}

\author{
Putu Dyah Prastiti Sukma Febriany, Ida Ayu Putu Widiati, I Wayan Arthanaya \\ Fakultas Hukum, Universitas Warmadewa
}

\begin{abstract}
ABSTRAK
Sumber daya alam merupakan tumpuan utama bagi setiap pembangunan yang ada Negara Indonesia, sehingga tanpa disadari perlahan sedikitnya tidak diantaranya memicu pencemaran dan/atau perusakan lingkungan hidup. Oleh karena itu, diperlukannya penegakan hukum yang tercermin dari peraturan perundang-undangan. Permasalahan dari penelitian ini adalah: 1) Bagaimana prosedur penanganan pengaduan akibat pencemaran dan/atau perusakan lingkungan hidup? 2) Bagaimana penerapan sanksi paksaan pemerintah pada PT. Mirtasari Hotel Development? Tipe penelitian dan pendekatan masalah yang digunakan adalah yuridis empiris dan yuridis sosiologis. Sumber bahan hukum yang digunakan sumber bahan hukum primer dan sumber hukum sekunder. Teknik pengumpulan bahan hukum yang digunakan yaitu teknik study pustaka dan lapangan. Serta bahan hukum yang dikumpulkan diolah dan dianalisis dengan menggunakan argumentasi hukum. Adapun hasil dari penelitian ini adalah prosedur penanganan pengaduan akibat pencemaran dan/atau perusakan lingkungan hidup akan ditindaklanjuti oleh instansi atau lembaga PPLH atau PPLHD yang terlebih dahulu telah menerima pengaduan langsung maupun tidak langsung, yang kemudian ditindaklanjuti dengan beberapa tahapan, yaitu: tahapan persiapan, pelaksanaan verifikasi lapangan, analisa data, dan terakhir menyusun laporan verifikasi pengaduan. Penerapan sanksi administrasi pemerintah pada PT. Mirtasari Hotel Development diberikan oleh Menteri Lingkungan Hidup berupa tindakan paksaan untuk segera melengkapi izin terkait penyimpanan sementara limbah B3, pembuangan air limbah, penyerahan limbah B3 kepada pihak ketiga, serta melengkapi fasilitas sesuai aturan dalam penyimpanan sementara limbah B3.
\end{abstract}

Kata Kunci: Pencemaran dan/atau Perusakan Lingkungan Hidup, Paksaan Pemerintah

\begin{abstract}
Natural resources are the main foundation for any development that exists in the Indonesian State, so that without realizing it slowly at least not one of them triggers environmental pollution and / or destruction. Therefore, it is necessary to enforce the law as reflected in statutory regulations. The problems of this research are: 1) What is the procedure for handling complaints due to environmental pollution and / or destruction? 2) How is the implementation of government coercive sanctions at PT. Mirtasari Hotel Development? The type of research and problem approach used are juridical empirical and juridical sociology. The source of legal materials used is primary legal material and secondary legal source. Legal material collection techniques used are literature and field study techniques. The legal materials collected are processed and analyzed using legal arguments. The results of this study are the procedures for handling complaints due to environmental pollution and / or destruction will be followed up by PPLH or PPLHD agencies or institutions that have received direct or indirect complaints, which are then followed up in several stages, namely: preparation, implementation. field verification, data analysis, and finally compiling a complaint verification report. The application of government administrative sanctions at PT. Mirtasari Hotel Development was granted by the Minister of the Environment in the form of coercive action to immediately complete permits related to temporary storage of B 3 waste, disposal of waste water, handover of B3 waste to third parties, as well as complete facilities according to the regulations for temporary storage of $B 3$ waste.
\end{abstract}

Keywords: Environmental Pollution and / or Destruction, Government Coercion

\section{PENDAHULUAN}

Indonesia adalah salah satu negara yang memiliki surnber daya alam yang melimpah dan beraneka ragam jumlahnya, sehingga dengan adanya pemanfaatan sumber daya alam maka keuntungan dalam jumlah besar mampu diperoleh. Seperti, yang kita ketahui pembangunan gedung yang dilakukan oleh pelaku usaha beberapa tahun ini semakin meningkat, dan merupakan pilihan bagi mereka guna memperluas cabang dan meningkatkan usaha yang mereka rintis. Bagi mereka selaku pelaku usaha beranggapan bahwa keputusan mereka tersebut mampu memberi manfaat bagi masyarakat sekitar dengan menyediakan lapangan pekerjaan serta mampu meningkatkan pendapatan 
nasional. Akan tetapi, sedikit dari mereka yang menyadari bahwa kegiatan pembangunan yang terus meningkat tanpa adanya upaya perlindungan dan pengelolaan sumber daya alam dengan baik dan benar, tentu hal ini meningkatkan pula timbulnya risiko pencemaran dan/atau perusakan lingkungan hidup, yang jika berlangsung terus menerus dapat menurunkan kualitas dan daya dukung lingkungan hidup serta merusak keseimbangan alam.

Berdasarkan temuan fakta kasus yang termuat pada Salinan Keputusan Menteri Lingkungan Hidup dan Kehutanan Nomor SK.983/Menlhk-PHLHK/PPSA/GKM.0/3/2017 tentang Penerapan Sanksi Administratif Paksaan Pemerintah Kepada PT. Mirtasari Hotel Development (Prama Sanur Beach Bali) tertanggal 9 Maret 2017, terkait perihal laporan peninjauan lapangan terhadap penerapan sanksi administrasi paksaan pemerintah kepada PT. Mirtasari Hotel Development (Prama Sanur Beach Bali), maka dengan ini pula melatarbelakangi penulis untuk menganalisa kasus tersebut dengan didasari oleh peraturan hukum yang bersifat umum serta peristiwa konkret terkait kasus tersebut yang terjadi di masyarakat.

Penelitian-penelitian serupa, yaitu penelitian yang mengkaji rumusan yang serupa tetapi dengan hasil yang berbeda salah satunya mengenai penerapan sanksi administratif dalam penegakan hukum lingkungan di Indonesia oleh (Panambunan, 2016), lainnya mengenai penerapan sanksi administrasi bagi perusahaan perkebunan yang melakukan pelanggaran hukum di bidang perkebunan oleh (Manurung, Pakpahan, Tania, Suhendro, \& Marpaung, 2020), dan terakhir mengenai penerapan sanksi administrasi dalam hukum perlindungan konsumen oleh (Herlina, 2019).

ermasalahan yang akan diangkat, yakni bagaimana prosedur penanganan pengaduan akibat pencemaran dan/atau perusakan lingkungan hidup? Bagaimana penerapan sanksi paksaan pemerintah pada PT. Mirtasari Hotel Development? Dalam melakukan suatu penelitian tentu terdapat tujuan yang ingin dicapai oleh peneliti. Tujuan dari penulisan penelitian ini, yaitu Untuk mengetahui prosedur penanganan pengaduan akibat pencemaran dan/atau perusakan lingkungan hidup dan untuk mengetahui penerapan sanksi paksaan pemerintah pada PT. Mirtasari Hotel Development.

\section{METODE PENELITIAN}

Metode penelitian merupakan cara melakukan sesuatu dengan menggunakan pikiran secara saksama untuk tercapainya suatu tujuan dengan cara mencari, mencatat, merumuskan dan menganalisis sampai menyusun laporan (Narbuko \& Achmadi, 2003). Tipe penelitian yang digunakan adalah yuridis empiris yang merupakan jenis penulisan hukum sosiologis dan dapat disebut pula dengan penelitian lapangan, yaitu mengkaji ketentuan hukum yang berlaku serta apa yang terjadi dalam kenyataan di masyarakat (Marzuki, 2010). Pendekatan penelitian dalam membahas setiap rumusan masalahnya menggunakan pendekatan yuridis sosiologis yakni merupakan suatu pendekatan terhadap masalah yang bertujuan memperoleh pengetahuan hukum empiris dengan turun langsung ke lapangan atau objeknya yaitu mengetahui penanangan pengaduan pencemaran dan/atau perusakan lingkungan terkait dengan penerapannya sanksi administratif paksaan pemerintah.

Dalam melakukan penyusunan penelitian ini, sumber bahan hukum yang digunakan ada 3, yakni (Soekanto \& Mamudji, 2018):

1. Data Primer

Data Primer adalah data yang diperoleh melalui penelitian lapangan dengan cara mewawancarai secara langsung dengan pihak yang berkompeten di bidang I Dinas Lingkungan Hidup Provinsi Bali dan di PT. Mirtasari Hotel Development (Prama Sanur Beach Bali).

2. Data Sekunder

Data sekunder adalah data yang diperoleh melalui studi kepustakaan yaitu melalui literatur atau buku-buku, peraturan perundang-undangan dan dokumen lainnya yang ada sebelumnya yang mempunyai hubungan erat dengan masalah yang dibahas, yaitu : Undang-undang Dasar Negara Republik Indonesia Tahun 1945; Undang-undang Republik Indonesia Nomor 32 Tahun 2009 Tentang Perlindungan dan Pengelolaan Lingkungan Hidup; Peraturan Menteri Negara Lingkungan HidupNomor 09 Tahun 2010 Tentang Tata Cara Pengaduan Dan Penanganan Pengaduan Akibat Dugaan Pencemaran Dan/Atau Perusakan Lingkungan Hidup; Peraturan Menteri Lingkungan Hidup Republik Indonesia Nomor 2 Tahun 2013 tentang Pedoman Penerapan Sanksi Dibidang Perlindungan Dan Pengelolaan Lingkungan Hidup; Peraturan Pemerintah Republik Indonesia Nomor 101 Tahun 2014 Tentang Pengelolaan Limbah Bahan Berbahaya Dan Beracun, KeputusanMenteri Negara Lingkungan Hidup Nomor : Kep- 
52/Menlh/10/1995 Tentang Baku Mutu Limbah Cair Bagi Kegiatan Hotel, Peraturan Menteri Lingkungan Hidup Republik Indonesia Nomor 5 Tahun 2014 Tentang Baku Mutu Air Limbah.

Penyusunan penulisan karya ilmiah skripsi ini, penulis melakukan pelitian di dua tempat yaitu:

1. Dinas Lingkungan Hidup Provinsi Bali yang ditunjuk langsung oleh Menteri Lingkungan Hidup untuk melakukan pemantauan penerapan sanksi administratif tersebut, beralamat di Jalan D.I. Panjaitan, Nomor 1, Renon, Panjer, Denpasar Selatan, Kota Denpasar

2. Hotel Prama Sanur Beach Bali yang merupakan usaha dari PT. Mirtasari Hotel Development yang mendapat teguran sekaligus pengenaan sanksi paksaan pemerintah dari Menteri Lingkungan Hidup, beralamat di Jalan Cemara Sanur, Sanur Kauh, Denpasar Selatan, Kota Denpasar.

Dalam rangka memperoleh data yang relevan dengan pembahasan tulisan ini, maka penulis melakukan teknik pengumpulan data sebagai berikut: study pustaka dan study lapangan.

Data yang dikumpulkan dalam penelitian ini baik dari data primer maupun data sekunder disusun secara sistematis, diolah dan dianalisis secara kualitatif dengan menggunakan interprestasi hukum dan argumentasi hukum secara deduktif-induktif setelah itu hasilnya disajikan secara deskriptif analisis (suatu cara berpikir yang didasarkan pada fakta-fakta yang bersifat umum dilanjutkan dengan penarikan kesimpulan yang bersifat khusus untuk mengajukan saran-saran.

\section{HASIL PENELITIAN DAN PEMBAHASAN}

\section{Prosedur Penanganan Pencemaran dan/atau Perusakan Lingkungan Hidup}

Berdasarkan uraian pembahasan diatas, maka dapat dilihat bahwa prosedur penanganan pencemaran dan/atau perusakan lingkungan hidup secara keseluruhan telah termuat dalam beberapa peraturan tertulis, yaitu:

1. Undang-undang Nomor 30 Tahun 2014 yang membahas beberapa hal terkait wewenang dan kewenangan administrasi pemerintahan.

2. Peraturan Menteri Lingkungan Hidup Republik Indonesia Nomor 02 Tahun 2013 yang membahas beberapa hal terkait tentang tahapan-tahapan penerapan sanksi administratif di bidang perlindungan dan pengelolaan lingkungan hidup yang dianalisis lebih dalam terhadap kasus yang menimpa PT. Mirtasari Hotel Development.

3. Undang-undang Nomor 32 Tahun 2009 yang membahas beberapa hal terkait tentang upaya perlindungan dan pengelolaan lingkungan hidup.

4. Peraturan Menteri Negara Lingkungan Hidup Nomor 09 Tahun 2010 yang membahas beberapa hal terkait tentang bagaimana prosedur atau tata cara pengaduan dan penangan terkait pencemaran dan/atau perusakan lingkungan hidup, yang termuat pada Pasal 11 sampai dengan Pasal 21.

\section{Penerapan Sanksi Paksaan Pemerintah pada PT. Mirtasari Hotel Development}

Sanksi adalah cara-cara menerapkan suatu norma atau peraturan. Sanksi hukum adalah sanksi-sanksi yang digariskan atau diotorisasi oleh hukum (Masriyani, Islah, \& Badri, 2016; Saputra, 2020).

a) Fakta Hukum

Berdasarkan dokumen yang dikeluarkan Badan Lingkungan Hidup Provinsi Bali (2017) bahwa menunjuk surat tugas kepala BLH Prov. Bali Nomor 177 Tahun 2017 tanggal 13 April 2017, tim Dinas Lingkungan Hidup Provinsi Bali telah melakukan pengawasan di PT. Mirtasari Hotel Development (Prama Sanur Beach Bali), pada tanggal 18 April 2017 dengan inti hasil temuan lapangan sebagai berikut:

i. PT. Mirtasari Hotel Development (Prama Sanur Beach Bali) berdiri diatas lahan $70.900 \mathrm{M}^{2}$ dengan jumlah kamar 426 Kamar dan jumlah tenaga kerja 414 orang.

ii. Perusahaan sudah melakukan identifikasi, pencatatan, pendataan dan pelaporan terhadap seluruh limbah B3 yang dihasilkan.

iii. Jenis limbah B3 yang dihasilkan berupa: oli bekas, lampu bekas, kaleng bekas dab batere bekas.

iv. Perusahaan sudah memiliki tempat penyimpanan sementara limbah B3, namun belum memenuhi ketentuan teknis dan belum memiliki izin TPS LB3. 
v. Perusahaan belum memiliki kerjasama dengan pihak ketiga untuk pengelolaan lanjutan LB3.

vi. Perusahaan sudah memiliki IPAL (Istalasi Pengelolaan Air Limbah) namun belum berfungsi optimal.

vii. Perusahaan belum memiliki izin pembuangan limbah cair karena terkendala hasil uji air limbahnya masih melebihi baku mutu yang ditentukan (Pergub. Nomor 16 Tahun 2016).

Bahwa berdasarkan pengawasan penataan lingkungan hidup pada tanggal 26 Oktober 2016 oleh pejabat pengawas lingkungan hidup (PPLH) kementerian lingkungan hidup dan kehutanan yang dilakukan terhadap PT. Mirtasari Hotel Development, telah terbukti melakukan pelanggaran terhadap peraturan perundang-undangan di bidang perlindungan dan pengelolaan lingkungan hidup, izinh lingkungan dan izin perlindungan dan pengelolaan lingkungan hidup.

b) Hasil wawancara dengan pihak Dinas Lingkungan Hidup Provinsi Bali yang disajikan dalam bentuk narasi.

Hari / tanggal

Pukul

24 Agustus 2018

Tempat

07.00 WITA

Narasumber

Dinas Lingkungan Hidup Provinsi Bali

Jabatan Narasumber

Dra. Luh Astrini

Pewawancara

Penata Tk. I Dinas Lingkungan Hidup Provinsi Bali

Tema Wawancara

Putu Dyah Prastiti Sukma Febriany

Tujuan Wawancara

Penerapan sanksi pa
Hotel Development.

: Untuk mengetahui penerapan sanksi paksaan pemerintah terhadap PT. Mirtasari Hotel Development.

Hasil wawancara dengan narasumber dipaparkan dalam bentuk narasi agar mempermudah pembaca memahami informasi yang telah didapatkan yang berkaitan dengan penerapan sanksi paksaan pemerintah terhadap PT. Mirtasari Hotel Development.

Dokumen yang dilampirkan dalam skripsi merupakan serangkaian dokumen yang berkaitan dengan Penerapan Sanksi Administrasi Paksaan Pemerintah kepada PT. Mirtasari Hotel Development (Prama Sanur Beach Bali). Dalam hal ini, PT. Mirtasari Hotel Development (Prama Sanur Beach Bali) telahmelakukan pelanggaran dalam perihal perizinan dan permasalahan limbah B3.

PT. Mirtasari Hotel Development (Prama Sanur Beach Bali) ikut dalam kegiatan PROPER dan dua kali berada dalam keadaan merah, dalam artian uji baku mutu melebihi ketentuan yang seharusnya dipenuhi, sehingga hal tersebut yang memicu teguran dan penerapan sanksi administrasi paksaan pemerintah kepada PT. Mirtasari Hotel Development (Prama Sanur Beach Bali).

c) Hasil wawancara dengan pihak PT. Mirtasari Hotel Development (Prama Sanur Beach Bali) yang disajikan dalam bentuk narasi.

Hari / tanggal $\quad: 07$ Februari 2018

Pukul : 10.00 WITA

Tempat $\quad$ : PT. Mirtasari Hotel Development (Prama Sanur Beach Bali)

Narasumber dan Jabatan:

1. Agung Arinata yang menjabat sebagai Human Resource Management (HRM) Prama Sanur Beach-Bali

2. Erwin Lewi yang menjabat sebagai Chief Engineering Prama Sanur Beach-Bali

Pewawancara $\quad:$ Putu Dyah Prastiti Sukma Febriany

Tema Wawancara : Penerapan sanksi paksaan pemerintah terhadap PT. Mirtasari Hotel Development.

Tujuan Wawancara $\quad$ : Untuk mengetahui faktor penyebab dikenakannya sanksi paksaan pemerintah dan sanksi yang sudah dilaksanakan oleh PT. Mirtasari Hotel Development. 
Hasil wawancara dengan narasumber dipaparkan dalam bentuk narasi agar mempermudah pembaca memahami informasi yang telah didapatkan yang berkaitan dengan penerapan sanksi paksaan pemerintah terhadap PT. Mirtasari Hotel Development.

Hotel Prama Sanur Beach Bali dinyatakan mendapat peringkat merah dalam kegiatan PROPER, karena ada beberapa hal yang belum dilakukan atau dikelola sesuai dengan peraturan perundang-undangan yang berlaku terkait dengan pengelolaan dan perlindungan lingkungan hidup yang dimiliki oleh pihak Hotel.

Faktor utama penyebab dari dijatuhkannya penerapan sanksi paksaan pemerintah pada Hotel adalah kurangnya pemahaman mengenai pengelolaan dan perlindungan lingkungan hidup terkait dengan penyimpanan limbah B3 dan izin pembuangan air limbah yang dilakukan oleh pihak Hotel. Dengan dijatuhhkannya sanksi paksaan pemerintah, pihak hotel perlahan memperbaiki kekurangan-kekurangan atau atau kekalalaian yang sebelumnya dilakukan terkait dengan sistem pengolahan dan perlindungan lingkungan hidup.

Pihak Hotel juga mengatakan bahwa kesalahan mutlak tidak sepenuhnya ada pada mereka terkait penjatuhan sanksi tersebut. Hal ini dikarenakan, pihak Hotel merasa pada saat itu, kurangnya sinkron atau koordinasi dengan beberapa pihak yang bersangkutan yang memiliki peran dalam pengawasan maupun penegakan norma-norma yang berlaku yang harus dijalankan oleh setiap orang/badan usaha yang memiliki kewajiban dan/atau tanggung jawab pada pengelolaan dan perlindungan lingkungan hidup.

Berdasarkan uraian pembahasan diatas, maka dapat dilihat bahwa sanksi paksaan pemerintah perlu diterapkan pada pihak PT. Mirtasari Hotel Development (Prama Sanur Beach Bali), sebagai efek jera atas bentuk pelanggaran yang telah dilakukan oleh pihak Hotel tersebut. Dan, pihak Pemerintah dan/atau instansi (lembaga) yang memiliki wewenang dalam penegakan hukum terkait permasalahan lingkungan hidup diharapkan lebih cermat dalam mengatasi permasalahan dan lebih diperketat agar setiap orang/badan usaha yang memiliki usaha dan/atau kegiatan tetap menjalankan kewajibannya disamping mendapatkan haknya untuk pemanfaatan sumber daya alam.

\section{SIMPULAN DAN SARAN}

\section{Simpulan}

2. Prosedur pengaduan pencemaran dan/atau perusakan lingkungan hidup diawali dengan adanya pengaduan oleh orang perseorangan, kelompok orang, badan hukum, atau instansi pemerintah yang mengadukan dugaan terjadinya pencemaran dan/atau perusakan lingkungan hidup. Pengaduan tersebut ditunjukkan dan/atau disampaikan kepada Instansi Penanggung Jawab baik secara langsung maupun tidak langsung. Pengaduan paling sedikit memuat informasi terkait pencemaran dan/atau perusakan lingkungan hidup yang hendak dilaporkan, yang kemudian disampaikan ke Instansi Penanggung Jawab. Setelah adanya pengaduan, maka instansi atau lembaga PPLH atau PPLHD akan menindak lanjuti pengaduan tersebut dengan beberapa tahapan, yaitu: tahapan persiapan, pelaksanaan verifikasi lapangan, analisa data, dan terakhir menyusun laporan verifikasi pengaduan.

3. Penerapan sanksi paksaan pemerintah perlu diterapkan pada pihak PT. Mirtasari Hotel Development (Prama Sanur Beach Bali), sebagai efek jera atas bentuk pelanggaran yang telah dilakukan oleh pihak Hotel tersebut. Penerapan sanksi administrasi pemerintah pada PT. Mirtasari Hotel Development diberikan oleh Menteri Lingkungan Hidup berupa tindakan paksaan untuk segera melengkapi izin terkait penyimpanan sementara limbah B3, pembuangan air limbah, penyerahan limbah B3 kepada pihak ketiga, serta melengkapi fasilitas sesuai aturan dalam penyimpanan sementara limbah B3.

\section{Saran}

1. Untuk pemerintah perlu dipertahankan dalam hal penegakan hukum lingkungan supaya segala bentuk permasalahan terkait pencemaran dan/atau perusakan lingkungan dapat terminimalisir.

2. Untuk masyarakat, terutama pelaku usaha wajib mentaati segala peraturan yang berlaku agar mendukung pembangunan berwawasan lingkungan dan berkelanjutan.

DAFTAR PUSTAKA

Herlina, N. (2019). Penerapan Sanksi Administrasi Dalam Hukum Perlindungan Konsumen. Galuh Justisi, 7(2). 
Manurung, H. P., Pakpahan, K., Tania, V., Suhendro, R. A., \& Marpaung, M. F. (2020). Penerapan Sanksi Administrasi Bagi Perusahaan Perkebunan Yang Melakukan Pelanggaran Hukum Di Bidang Perkebunan. Ius Civile: Refleksi Penegakan Hukum Dan Keadaan, 4(2).

Marzuki, P. M. (2010). Penelitian Hukum (VI). Jakarta: Predana Media Group.

Masriyani, Islah, \& Badri, M. (2016). Penerapan Sanksi Administrasi Terhadap Perusahaan Yang Menimbulkan Pencemaran Sungai Di Kabupaten Muaro Jambi Berdasarkan Perda Nomor 6 Tahun 2012. Jurnal Lex Special, (24).

Narbuko, C., \& Achmadi, A. (2003). Metodelogi Penelitian. Jakarta: PT. Bumi Aksara.

Panambunan, A. M. K. (2016). Penerapan Sanksi Administratif dalam Penegakan Hukum Lingkungan di Indonesia. Lex Administratum, 4(2).

Saputra, A. D. (2020). Penerapan Sanksi Pelanggaran Administratif Pemilu bagi Penyelenggara Pemilu. Jurnal Ilmu Hukum: LL-DIKTI Wilayah IX Sulawesi, 9(2).

Soekanto, S., \& Mamudji, S. (2018). Penelitian Hukum Normatif Suatu Tinjauan Singkat (Cetakan Delapan). Jakarta: Rajawali Pers.

Peraturan Menteri Negara Lingkungan Hidup Nomor 09 Tahun 2010 Tentang Tata Cara Pengaduan Dan Penanganan Pengaduan Akibat Dugaan Pencemaran Dan/Atau Perusakan Lingkungan Hidup. 